\title{
APPLICATIONS OF COLLAGEN IN MEDICAL DEVICES
}

\author{
John A.M. Ramshaw, PaUl R. VAughan AND Jerome A. Werkmeister \\ CSIRO Molecular Science, Victoria, Australia
}

\begin{abstract}
Collagen is the most abundant natural protein found in living systems. While there is a whole family of different collagen types, each differing in sequence, the properties that make this protein so attractive as the building blocks for medical devices, are reflected largely by the unique fibrillar structure of the molecule, as well as defined functional regions that interact with the surrounding cells and other matrix components. As a commercial medical product, collagen can be part of the natural tissue used in the device, or it can be fabricated as a reconstituted product from animal or recombinant sources. Both types of uses have distinct properties that convey advantages and disadvantages to the end product. This review examines the chemistry and biology of collagen and describes some well-documented examples of collagen-based medical devices produced in one or other of these formats.
\end{abstract}

Biomed Eng Appl Basis Comm, 2001 (February); 13: 14-26.

Keywords: Collagen; Biomaterials; Matrix; Vascular prosthesis; Adhesion barrier; Recombinant; structure-function

\section{INTRODUCTION}

Collagen in various forms has now become a successful and widely used medical material. It has gained widespread clinical and consumer acceptance, being seen as a safe material with properties that can be adapted to meet a range of different clinical applications (1). Commercial products are now readily available for use in a variety of medical disciplines. For example, products for cardiology include bioprosthetic heart valves (2), arterial replacements $(3,4)$, and arteriovenous access shunts (5). In surgery, collagenbased sutures (which have been used since historic times) and haemostats (6) are available. For wound management, a range of wound dressings is now available $(7,8)$, while for tissue augmentation, collagen pastes have been used extensively in dermal applications (9) as well as for treatment of urinary inconti-

Received: Jan. 29, 2001; accepted: Feb. 15, 2001

Address for correspondence: John A.M. Ramshaw, CSIRO Molecular Science, 343 Royal Parade, Parkville, Victoria 3052, Australia nence (10). As the demand for more sophisticated and innovative products rise, the more recent and successful products have arisen through an understanding of the structure, function and properties of collagen in the extracellular matrix of natural tissues. It is this knowledge that will be important to further developments in this expanding field, and in the development of successful products in the emerging area of tissue engineering where production of an accurate, functional matrix is essential.

\section{COLLAGEN STRUCTURE AND PROPERTIES}

As a major, natural material of the body, collagen has for a long time been seen as having great potential as an ideal biomaterial (1). Collagen is the major protein of all connective tissues, including skin, bone, tendon and cartilage. For example, in skin it forms the large fibre bundles, which give skin its strong yet flexible structure, each bundle being made up of many individual collagen fibrils. Collagen fibrils show a characteristic banded structure when examined at high magnification by transmission electron microscopy. 
Collagen is generally used as a generic term to cover a large family of distinct proteins. Thus, there are at least 19 genetically distinct types (11). Each is characterised by having the triple-helical motif as part of its structure and each plays a distinct structural role in the extracellular matrix. The major, most abundant collagens (types I, II and III) form the structural fibrils of tissues, while the others play roles in association with these fibrils (the fibrillar-associated collagens with interrupted triple helices - FACIT collagens) or in networks (e.g., type IV) or in linking structures (e.g., type VII) $(11,12)$.

The characteristic feature of all collagens is the triple helix motif. In this structure, 3 individual chains, each in a left handed polyproline II-like helix, are wound together to form a right handed, supercoiled triple helix, which has a rope-like structure (13). A consequence of this structure is that collagens show a characteristic repeating sequence, (Gly-Xaa-Yaa) $)_{n}$. Glycine is found in every third position since it is the only amino acid that is small cnough to pack into the centre of the triple-helical structure (13). While the $X a a$ and Yaa positions could be any amino acid, they are frequently (about 20\% overall) the imino acid proline, which, in the Yaa position, is normally altered by post-translational modification to 4-hydroxyproline. This modification enhances the stability of the triplehelix (14). The occurrence of other amino acids in the Xaa and Yaa positions shows distinct preferences. For example, large aliphatic and aromatic residues are rarely found in the Yaa position, possibly due to steric constrains on packing (15), while Arg is much more frequent in the Yaa position, probably due to its capacity to stabilise the triple-helix in this position (16).

In mature collagenous tissues, the individual molecules are packed into fibrils or other specific arrangements and the molecules are cross-linked together via a specific pathway using the enzyme lysyl oxidase (17).

\section{COLLAGEN AS A BIOMATERIAL}

The format of the collagen in medical devices leads 10 materials with a range of distinct properties. Two principle approaches for collagen processing are used. In one, the devices are tissue-based, where the defined shape of the tissue is retained as part of the function of the device. An good example of this is the bioprosthetic heart valve. In these devices, chemical fixation, typically with glutaraldehyde, is used to give strength and durability to the device (18). This processing also masks the immunogenicity of the tissue (19), although some sites for cell-matrix interactions may be lost. The principle drawback to this approach is the tendency for these materials to show nonspecific calcification that can impair the long-term function of the device. Various approaches have been examined to minimise or eliminate this calcification (20), but without full success.

The other approach is 10 use purified collagen. In this case, collagenous tissue is disrupted and is generally made soluble though use of an enzyme digestion step that removes the cross-link regions while leaving the triple-helix intact (21). The soluble collagen can then be purified to remove potential immunogenic contaminants. Alternatively, the collagen is comminuted to very fine particles that can be washed clean of impurities, either before or after this processing (1). The purified collagen can then be reconstituted into the desired shape or form for the product. If necessary, the product can then be stabilised, either by a chemical fixation method such as mild glutaraldehyde treatment (18), or by a physical method such as dehydrothermal cross-linking (22). Examples include the formation of dry, stabilised collagen sheets for wound dressings: (7), or preparation of collagen paste for sott tissue augmentation (9). Reconstituted products are characterised by a high biochemical purity associated with low immunogenicity, controlled turnover, often over short time periods, controlled porosity and retention of cell-matrix interactions that are important in biological functions in tissucs. They come in a range of formats, including porous sheets for wound dressings (7), low porosity sheets as adhesion harriers (23), collagen paste for tissue augmentation (9), clear gels for ophthalmic applications (24) and molded shapes for meniscal repair (25).

The most recent development is the availability of recombinant collagens (26). This allows the production of natural human collagens that are of high purity and discase free. A recombinant process can be used to produce all types of collagens, including those that are of very low abundance in natural tissue and so not readily obtained in commercially practical quantitics by traditional tissue extraction methods. These minor collagens may, however, have unique biological properties that are valuable for particular clinical applications. Recombinant approache's give opportunitics also for the production of non-natural molccules where specific siles, for example the collagenasc cleavage site have been modified, and for other designed mole. cules based on the triple helical motif that may have applications as scaffolds in tissue engineering for the enhancement of specific cell growth (27).

The biosynthesis of collagens is complex and involves a large number of secondary modificalion steps many of which arc unique to collagen and collagenlike molecules (12). These include specific hydroxylation of certain Lys and Pro residues, glycosylation of hydroxyl.ys residues and conversion of Lys in the klopeptides to aldehyde as part of the cross-linking process. Culture of natural or transformed mammalian cells can be used to produce collagen, as clcarly the 
full complement of enzymes necessary for collagen production are already present, but the yield of product is low and complex media are required (28). Fortunately, in order to mimic collagen biosynthesis in a recombinant system only one of these extra processes is essential for producing a stable, collagen molecules. This step is the hydroxylation of Pro residues by the enzyme prolyl-4-hydroxylase ( $\mathrm{P} 4 \mathrm{H})$. This enzyme acts on Pro residues in the Yaa-position in the repeating collagen sequence converting them to 4hydroxyproline. This step is essential if collagen is to be stable at body temperature. For example, it has been shown using cell culture that inhibition of this enzyme leads to a loss of at least $12^{\circ} \mathrm{C}$ in stability, reducing the collagen stability to well below body temperature (14). P4H comprises 2 chains, each with an $M_{r}$ of about 65,000 , and for activity requires $\mathrm{Fe}(\mathrm{II})$, oxygen, ascorbate and $\alpha$-ketoglutarate.

Although insect cells would be able to produce hydroxylated collagens using their own endogenous enzymes (26), this system, particularly the Baculovirus system, has been used extensively to characterise the requirements of a recombinant system $(26,29)$. These data have shown, for example, that for improved collagen yields both collagen and prolyl hydroxylase must be simultaneously expressed (30). Although this system bas proved very valuable for giving a better understanding of recombinant collagen production, again product yield is not high and so non-animal systems are now preferred (26).

There have been several reports of expression of collagen and collagen-like genes in $E$. coli, but these systems did not include functional $\mathrm{P} 4 \mathrm{H}$ and so the product would be a gelatine-like material $(31,32)$. On the other hand, several groups have reported the successful production of hydroxylated collagen using Saccharomyces systems (33-35). This can be achieved, for example, by using non-integrating, stable vectors. The collagen gene can be introduced under control of an $\mathrm{ADH}$ promoter while the $2 \mathrm{P} 4 \mathrm{H}$ genes can be introduced on a separate vector using a single bi-directional GAL promoter; collagen secretion can be achieved using yeast signal sequences (34). Other arrangements of the 3 genes on these vectors are also effective (36). Alternatively, the 3 genes can be introduced as multiple copies integrated into the yeast genome, all under the control of GAL promoters (35). This approach leads to excellent yields of collagen that has a high degree of prolyl hydroxylation, as shown by a stability (melting temperature) comparable to native, tissue derived collagen (35). The approach of chromosomal integration has also been used successfully in other yeasts, including Pichia and Hansenula $(37,38)$. In Hansenula, secretion can be effectively achieved using a native collagen signal sequence, but this approach is less effective in Pichia where yeast signal sequences are preferred (37). These systems produce fully hydroxylated collagens in commercial yields $(37,38)$.

Other non-microbial systems, including plants and transgenic animals (39-42), have also been described that allow the effective production of collagens. Of particular interest are the plant systems collagen where human homotimeric procollagen type I has been produced in transgenic tobacco. The product was processed at the C-propeptide end but the $\mathrm{N}$-propeptide was retained. The yields were of the order of $10 \mathrm{mg}$ collagen $/ 100 \mathrm{~g}$ powdered plant. However the collagen was not hydroxylated by the plant $\mathrm{P} 4 \mathrm{H}$ that has a different specificity, and consequently has a lower melting temperature of $30.5^{\circ} \mathrm{C}$, instead of $41.5^{\circ} \mathrm{C}$ of bovine collagen (39). Finally, transgenic mice have been produced with high levels of type I alpha 1 procollagen homotrimers found in the milk of lactating mice (40-42). This material was found to be posttranslationally modified by hydroxylation of proline and lysine and to be stably produced at levels of 20-80 $\mu \mathrm{g} / \mathrm{ml}$, varying from animal to animal.

\section{COLLAGEN IN MEDICAL DEVICES}

Collagen has now examined for use in a wide variety of clinical applications (Table I). These include areas where collagen products have been used regularly as materials of choice for specific indications for over 30 years. In other cases, the applications are still at a research level and have not as yet matured into effective products that are commercially available and that have received regulatory approval. The range of studies in the use of collagen in medical devices precludes a full description in this article. Therefore, we have focussed on a limited number of examples. These include a well-established, tissuederived vascular prosthesis and other potential applications for this technology. We also describe a research material based on purified, soluble collagen, to show the breadth of the materials properties and applications that have emerged for collagen. Finally, we discuss the emerging opportunities for recombinant collagenbased materials.

\section{A Vascular Prosthesis}

The Omniflow ${ }^{\text {TM }}$ Vascular Prosthesis (BioNova International, North Melbourne) is an example of a tissue-based collagen device. However, in this case the tissue has been formed to the desired shape and form through use of an implanted mandrel, rather than using a naturally occurring shape and form.

The concept of using a mandrel to form a defined tissue shape, in this case a tubular shape, derives from studies by Pierce and Baltimore (43) who showed that a fibrous tube could be formed around an implanted polypropylene mandrel. Subsequently Hufnagel (44) 
Table I. Development of concepts for collagen-based biomaterials.

\author{
Medical Area \\ Cardiovascular surgery \\ Dentistry \\ Dermatology \\ Dressings \\ Esophageal surgery \\ General surgery
}

Neurosurgery

Ophthalmology

Orthopaedics

Otology

Urology

Other
Application

Vessel replacement

Heart valves

Periodontal attachment

Alveolar ridge augmentation

Tissue augmentation

Augmentation

Hernia repair

Adhesion barriers

Hemostasis

Tissue adhesives

Nerve conduits

Nerve repair

Corneal graft

Vitreous replacement

Retinal retachment

Bone repair

Articular cartilage repair

Meniscal cartilage repair

Cruciate ligament rerepair

Tympanic membrane repair

Ureter replacement

Renal repair

Dialysis membrane

Urinary incontinence

Drug delivery

\section{Examples}

4,85

2,86

76,87

88

9,89

7,90

91,92

93,94

23,95

6

96

97,98

99

100

24

101

102,103

104

25,105

106

107,108

109

110

111

10

112,113 and also Assefi and Parsonnet (45) showed that an improved tube could be made if a reinforcing mesh was included with the mandrel. Sparks (46) later developed the metal "tissue die", which was extensively studied as a method for producing an autologous implant. This mandrel technology evolved through several variations, including incorporation of polyester mesh. However, after extensive clinical evaluation it was eventually abandoned as the devices were not durable and were failing due to dilatations and aneurysms. Parsonnet and colleagues (47) examined the use of silicone mandrels, in combination with polyester mesh. This group also introduced the use of xenogenic species along with chemical fixation (48). By this time glutaraldehyde fixation had become established technology in the manufacture of bioprosthetic heart valves (49) and umbilical vessel vascular prostheses (50). The key development by Ketharanathan (3) that led to a clinically successful vascular prosthesis was to combine in a single strategy all four elements - the use of a silicone mandrel, a polyester mesh, a xenogenic species (sheep) and chemical stabilisation (glutaraldehyde). This combination produces a fully integrated tissue-polymer composite (51) that is highly durable, like synthetic devices, and is biologically compatible, like natural vessels (4).

Specifically, the Omniflow ${ }^{\text {TM }}$ Vascular Prosthesis is made by implantation of $600-700 \mathrm{~mm}$ mandrels, made of $6 \mathrm{~mm}$ OD silicone tubing wrapped with a layer of knitted polyester mesh, bencath the cutancous trunci muscle of anaesthetized sheep. After about 12 weeks, the mandrels and the new collagenous capsule that surrounds the mesh are removed from the sheep and trimmed to remove excess tissue. The collagencoated mandrels are then processed using proprietary, glutaraldehyde-based, stabilisation of the collagen. Further trimming, and removal of the mandrel, gives the mesh-reinforced collagen conduits (Roberts and Edwards, 1992).

The clinical data for the Omniflow prostheses from a number of studies has proven excellent. For example, in a study of over 650 patients where Omniflow (270 implants) was compared to ePFTE (227 implants) or saphenous vein, the Omniflow proved equivalent or better than the ePTFE material dependent of the location of the replacement (53).

Clinically, the Omniflow prosthesis does not show intimal hyperplasia (Figure 1), a process that is a 


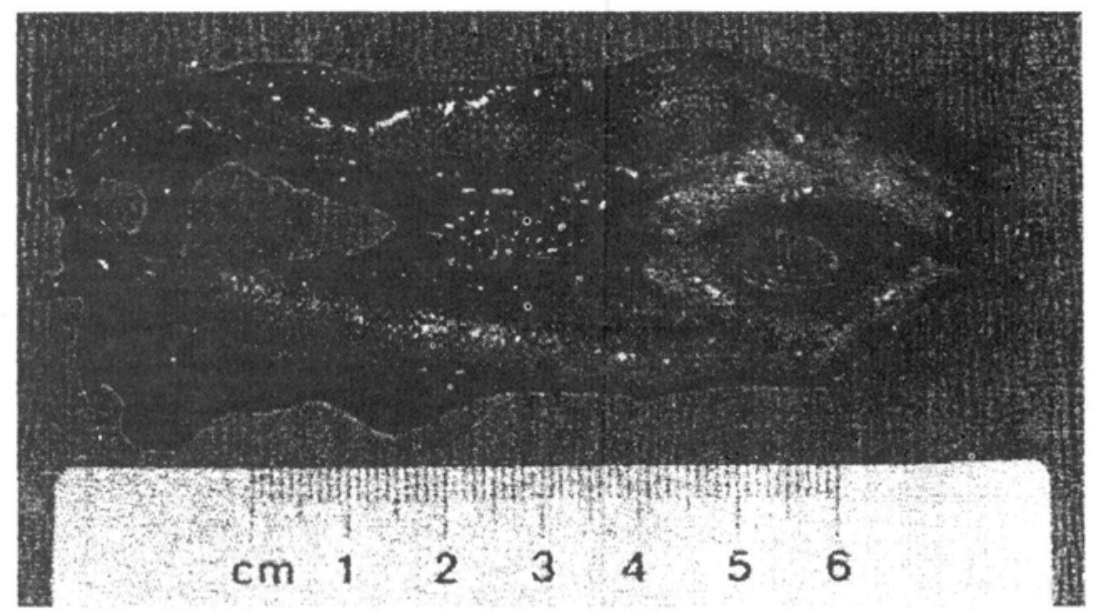

Fig. 1. Gross examination of a 6-month explant of the Omniflow ${ }^{\text {Th }}$ Vascular Prosthesis from a dog model showing a smooth thrombus-free inner surface and good tissue integration on the outside. The mesh is still clearly visible, confirming the absence of intimal hyperplasia.

significant issue in the long-term performance of ePFTE devices (54). In part, this may be due to the better mechanical match to natural vessels. Thus, Omniflow II has a compliance of 3.9 (percent diameter change / $\mathrm{mm} \mathrm{Hg} \mathrm{x10^{2 }}$ ) compared to values for human artery of 7.4 and saphenous vein of 2.7. On the other hand, ePTFE is much stiffer with a compliance of 1.8 . $(4,55)$

During the development of the current Omniflow ${ }^{\mathrm{TM}}$ Il device a range of animal studies extending out to 4 years indicated the durability of the device, and also confirmed that there was no intimal hyperplasia, nor any surface thrombus build up (56). Immunohistological analysis of samples from these studies, and also of subsequent clinically derived explant samples, has shown that retention of the collagen structure of the device and its extensive augmentation by new tissue can explain the excellent performance of the Omniflow prosthesis (57) when compared to earlier biological devices where failures from aneurysms and dilatations were common $(57,58)$. In order to use immunohistology to study the collagen of the device, a range of highly specific antibodies were developed (59-64). These antibodies are capable of distinguishing not just between different collagen types, but also for a given collagen type between different species (Figure 2). This library of antibodies allows the sheep collagen of the original device to be examined specifically in explant samples, even though new host derived collagen may be present (for example dog from model studies or human from clinical samples). These antibodies show the persistence of the original collagen. On the other hand, other antibodies allow specific examination of new, hostderived collagens of different types, even though persistent collagen from the original device is present.
This allows the rate and type of collagen augmentation of the device to be described (64-66).

These antibody tools have shown in animals that at 4 years the collagen of the original device persists, and is extensively augmented by new host (dog) derived collagens (56). At earlier time points, animal studies showed that the initial augmentation of the wall of the device, seen even at 1 month, was by type VI collagen, followed by type III collagen $(57,63,65)$. Clear augmentation was evident through the full thickness of the wall at 6 months for both collagen types (Figure 3A). Examination of clinical samples is limited by the availability of samples - the excellent performance means that few samples become available. Generally, those that do become available arise where the patient suffers further vascular disease problems that necessitate replacing natural vessel by additional prosthesis. In those cases, short samples from the original anastomosis become available which have generally been in the patient for many years. In such samples, various collagen types can be seen to have augmented the device throughout the full thickness of the wall $(57,64,66)$.

The immunohistological explant studies of the Omniflow vessel wall, depicting a sound structural matrix of old and new collagen proteins, provides a strong scientific rationale for the large clinical success of this device, particularly the noticeable absence of any signs of dilatations or aneurysms $(53,67,68)$. Two other important features for a successful blood vessel are haemocompatibility and an absence of intimal smooth muscle cell hyperplasia. Examination of both animal and human explants depict a neo-intima that is thicker at both anastomoses compared with the central regions of the vessel. This neointimal region comprises a number of connective tissue components, 


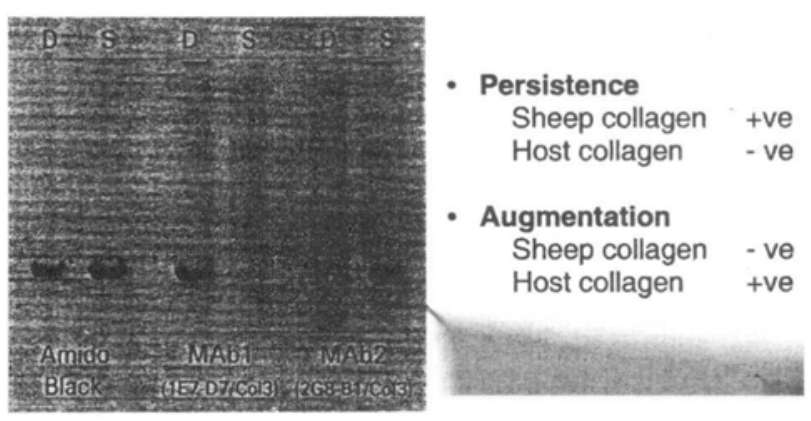

Fig. 2. Immunostaining of electroblots of $\operatorname{dog}(D)$ and sheep (S) type III collagens after gel electrophoresis run under native conditions. Staining was either with amido black to show protein or by immunostaining with specific monoclonal antibodies, demonstrating the ability of these antibodies to distinguish type III collagens from different species. The application of these antibodies to the study of the collagen composition in Omniflow ${ }^{\text {tw }}$ Vascular Prosthesis (sheep collagen) explants from a dog model is indicated.

including collagen types I, III, VI, IV, laminin and a number of microfibrillar elastin-like proteins $(53,64)$. All these connective tissue proteins are synthesized rapidly in this part of the vessel. While the original Omniflow device is not a classical porous device, like some of the purely synthetic analogues, the innermost region contains a very loosely packed collagenous layer (51) that allows for easy tissue infiltration (6366 ). Collagen type $V$ is seen at the carliest onset of neo-intimal formation and is localized on the innermost part of the layer (62). It is interesting to note that unlike the other collagen types, collagen type $V$ is an excellent passivating surface that discourages platelet binding and aggregation. This might be an important cascade of events that allows device stabilization at the blood contact zone. With time the entire neointimal layer becomes a rich reservoir of connective tissue components that has been shown to support endothelialisation (Figure 3B) (63-66). In animal studies, endothelial migration occurs from both anastomoses within one month of implantation and is complete by 3 to 6 months (69). In some early explants patchy endothelialisation is also seen, which suggests intramural migration of endothelial cells. Consistent with this, pockets of neo-vascularisation are common in animal explants. Clinical explants are limited to the anastomotic region where endothelial cells are present - like the anastomotic region in animal explants this zone, when analyzed by transmission electron microscopy, is complex comprising a multilayered structure of cellular debris, fibrin, and von Willebrand positive patches $(64,66)$. Smooth muscle cell intimal hyperplasia is not seen in these regions on both animal and clinical explants $(57,64,66)$.

Thus, the tissue polymer composite that forms the Omniflow prosthesis shows excellent biocompatibility as well as excellent strength and durability, associated with persistence of original collagen and augmentation by new host tissue. The blood contact surface is characterised by minimal intimal hyperplasia, with good, rapid endothelialisation in animal studies, although is clinical samples the extent of endothelial cell coverage is much more limited. Nevertheless, in clinical use the device has shown excellent long-term performance so lack of endothelial coverage is not a

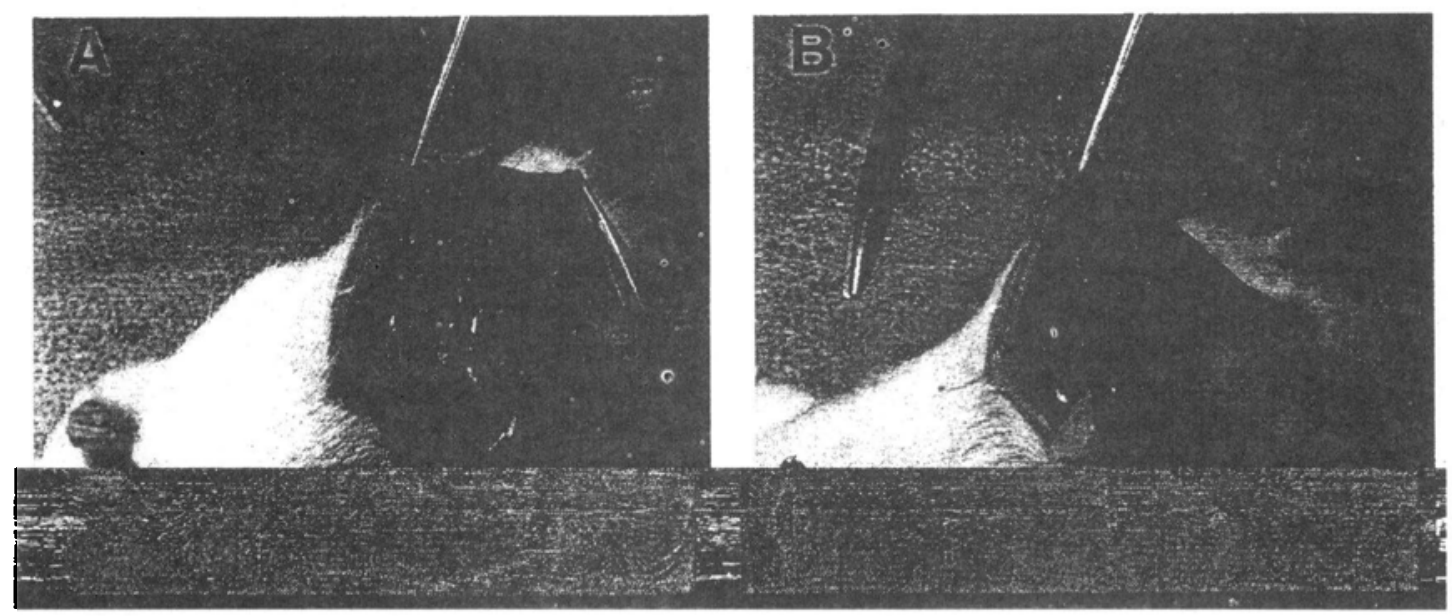

Fig. 3. Immunohistology of explants of the Omniflow ${ }^{\text {th }}$ Vascular Prosthesis from a dog model. Positive staining appears as white on a black background. (A) At 6 months, clear augmentation by collagen type II] was evident through the full thickness of the wall. The polyester bundles are visible (top left). (B) At 1 month, continuous diffuse von Willebrand factor staining is evident at the blood contact surface, indicating the progress of the endothelialisation process. Scale bars $=100 \mu \mathrm{m}$. 
critical issue for medium size ( 5 to $6 \mathrm{~mm}$ ) applications $(4,57)$.

The Omniflow tissue-polymer composite material is very versatile and can be used in non-vascular applications as well. For example, it has been shown to perform extremely well as a patch for abdominal wall repair (70). In this study, the material showed excellent durability and healing in rabbits, with clear vascularisation and cell coverage, while no calcification nor abdominal adhesions were observed (Figure 4A). In samples where the collagen porosity had been substantially reduced much slower healing was observed (Figure 4B). These data contrast with data for polypropylene mesh, the most commonly used material for this indication, which, in the same animal model system, showed uneven healing and poor vascularisation. There was limited cell coverage, consistent with frequent adhesions (70).

\section{An Adhesion Barrier}

Various groups have proposed that a collagenbased membrane could be effective as an adhesion barrier $(23,71)$. The example described here illustrates the use of soluble collagen that has been reconstituted into a fibrillar material and formed into a thin sheet. Adhesions are an abnormal fibrous connection between structures that are normally separate. They frequently form after surgery, for example after cardiac and gynaecological surgery, and are characterised by pain and dysfunction. They develop as a consequence of the tissue injury, due to prolonged presence of fibrin in association with excess connective tissue production.

An example of an adhesion barrier is one made from purified soluble collagen (23). This material was made through pepsin solubilisation of young bovine skin, and purification of the soluble collagen by $\mathrm{NaCl}$ fractionation at acid $\mathrm{pH}$. This collagen was then reformed into fibril-like material with the same ordered collagen packing that is found in native collagen through controlled precipitation with polyethylene glycol. This fibril-like mass was then made into thin membranes by a centrifugation approach and these films stabilised by gamma irradiation. This could then be dried, for example through use of solvent, and sterilised prior to animal implantation (23).

The effectiveness of this material was demonstrated in a standard rat model in which the peritoneum and underlying muscle were abraded while the caecum was exteriorised and the serosa also abraded. Silk sutures were inserted in the caecal wall and then the tissue replaced in contact or with the adhesion barrier intervening between the damaged tissues (72).

The collagen material showed good handling and was able to conform readily to the tissue contours lack of suture strength, however, could be a difficulty for certain applications where a tissue adhesive would not be suitable. After one month, examination of the wound showed that there were no serious adhesions. Overall, there was a uniform response with few adhesions, good healing of the injured surface and little or no fibrotic reaction (Figure 5). A quantitative assessment that scored the extent, tenacity and nature of the adhesions, if present, showed that even in a small cohort of 10 animals, the collagen barrier significantly reduced adhesions compared with that observed in a similar number of control animals where no barrier was employed. Histological examination confirmed that there was minimal tissue reaction (23).

A range of other materials has also been proposed as
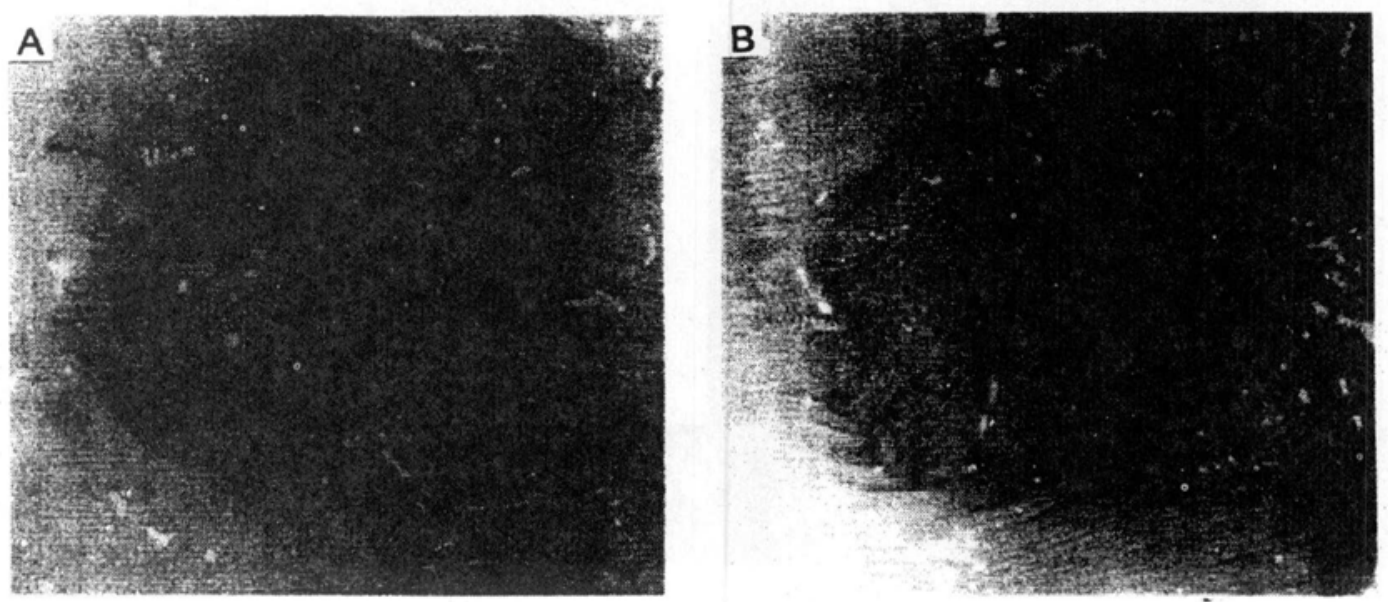

Fig. 4.Examination of the performance after 12 weeks of collagen-polymer composite materials, approximately $20 \times 20 \mathrm{~mm}$, for abdominal wall repair in a rabbit model. (A) Clear vascularisation and cell and new tissue coverage, is seen; no calcification nor abdominal adhesions were observed. (B) In samples where the collagen porosity had been substantially reduced, little vascularisation of new tissue coverage is seen, with the mesh component still clearly visible. 

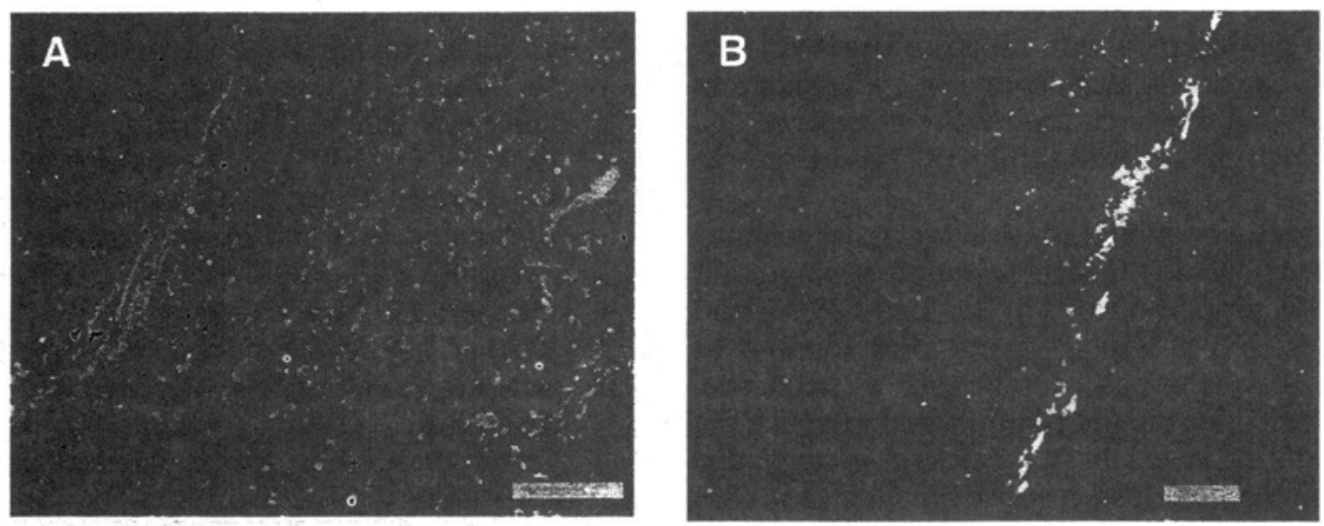

Fig. 4. Examination of the performance after 12 weeks of collagen-polymer composite materials, approximately $20 \times 20 \mathrm{~mm}$, for abdominal wall repair in a rabbit model. (A) Clear vascularisation and cell and new tissue coverage, is seen; no calcification nor abdominal adhesions were observed. (B) In samples where the collagen porosity had been substantially reduced, little vascularisation of new tissue coverage is seen, with the mesh component still clearly visible.

adhesion barriers, including PLGA (73), hyaluronan (74) and oxidised cellulose (75). Comparison of the collagen membrane with oxidised cellulose (Interceed $^{\mathrm{TM}}$, Ethicon) in the same animal model indicated that collagen performed better - variable tissue responses comprising adhesions, fibrosis of injured surface and thickening of the peritoneum were associated with certain of the cellulose implants (23).

Such membranes can have other clinical applications. An example is in the treatment of periodontal disease that is a highly prevalent problem for a significant proportion of the adult population. The cause of this disease is the bacterial deposits, "dental plaque", that forms at and around the gingival margin, providing a locus from which the disease progresses. In the final stages of the progression of this disease the bony support that is essential for the location and attachment of a tooth is progressively lost until its effectiveness becomes minimal and the tooth is lost. Treatment seeks to arrest and reverse this process. The disease pocket that forms can be cleaned, but the cpithelium of the gingiva can migrate rapidly and reform a pocket and preventing repair. Insertion of a membrane can stop this cell migration and allow bony tissue regeneration and new attachment to form (76). Initial products for this indication were non-resorbable synthetic polymer membranes that were limited in performance (77). A plain collagen membrane was shown, however, to perform well in a dog model, allowing good bone re-growth over a 9-week period (76). Collagen membranes have the potential for further improvement through incorporation of biologically active agents such as antibiotics and growth factors. Future directions could include tissue-engineered solutions where gene and cell delivery are incorporated into the product concept.

\section{Recombinant Materials}

Recombinant collagen is now available commercially for in vitro applications, so it is to be expected that registered medical products will be available shortly (78). Biochemically, the recombinant collagens mimic natural collagens, showing good hydroxylation of Pro residucs, and an ability to form fibrillar aggregates. The initial products are likely to be in areas such as haemostat materials, where recombinant type III is particularly effective (79) and products for soft tissue augmentation where recombinant type I collagen may be the most applicable. It is possible to modify the structures of these natural collagens to produce molecules with altered functionality. Products based on this approach will take longer to reach the market, but are cxpected to be useful in arcas such as tissue engineering. For example, the collagenase cleavage site is well defined for the major, fibril forming collagens, and cleavage at this site is a key step in the turnover of collagen. Thercfore, modification of this site would be expected to alter the turnover of recombinant collagen based biomaterials.

Alternatively, recombinant technology gives the opportunity to design novel molecules based on the triple helix motif but not equivalent to a natural collagen, or as chimeric molecules containing non-natural combinations of globular and triple-helical domains (27). Such constructs could contain, for example, multiple copies of a specific cell binding domain (27). Thus the $\alpha 2 \beta 1$ integrin binding regions have been defined for type I (80) and type III (81) collagens and could be incorporated into novel structures (27). Further, collagens are involved in a wide variety of other binding activities, including to growth factors, heparin, and a range of adhesive proteins (82), so definition of 
these sites will allow an expanded range of novel molecules to be designed with specific, targeted functions. Such constructs could prove very valuable in tissue engineering where control of the phenotype and biosynthetic activity of a specific cell type could be enhanced.

In designing a novel construct certain features should be considered. Codon selection is important since the high proportion of Gly codons (GGN) and Pro codons (CCN) presents opportunities for loss of message integrity through looping out of sequence. Also, codon selection should be optimised to match the tRNA availability in the host species, a strategy that has given enhanced yields for recombinant elastin (83). The product should also have adequate thermal stability. This can be achieved through sufficient Hyp incorporation. However, Arg in the Yaa position can also give comparable stability to the triple-helix (16). Selection of the other non-proline residues in the Xaa and Yaa positions can also affect overall stability. A comprehensive study using a host-guest peptide strategy has enabled the effects of all amino acids on stability to be determined (84). These data have shown, for example, that Gly-Gly sequences are destabilising, as are Phe and Tyr, particularly in the Yaa position. Asp residues in the Yaa position are also destabilising. However, in selecting the $\mathrm{Xaa}$ and Yaa residues a structure that is very stable and rigid may not be optimal and a degree of flexibility may be important to enable tight binding.

\section{CONCLUSIONS}

Research in many laboratories has clearly demonstrated that collagen can be used in a wide range of different medical devices. These medical devices are suitable for many distinct clinical applications, and in many cases have proven very successful in clinical use. There are many opportunities in the future for further commercial products, particularly in the emerging field of tissue engineering where collagen is a logical choice as the scaffold structures that are necessary for tissue regeneration.

\section{REFERENCES}

1. Ramshaw, J.A.M., Werkmeister, J.A. and Glattauer, V. (1995). Collagen-based biomaterials. Biotechnol. Genetic Eng Rev., 13, 335-382.

2. Ferrans, V.J., Hilbert, S.L., Tomita, Y., Jones, M. and Roberts, W.C. (1988). Morphology of collagen in bioprosthetic heart valves. In, Collagen, Vol. 3, M.E. Nimni (Ed.), CRC Press, Boca Raton, FL, pp. 145-190.

3. Ketharanathan, V. and Christie, B.A. (1980).
Glutaraldehyde-tanned ovine collagen conduits as vascular xenografts in dogs. Arch. Surg., 115, 967-969.

4. Ramshaw, J.A.M., Edwards, G.A., and Werkmeister, J.A. (1995). Tissue-polymer composite vascular prostheses. In, Encyclopedic Handbook of Biomaterials and Bioengineering, Wise, D.L., Trantolo, D.J., Altobelli, D.E., Yaszemski, M.J., Gresser, J.D. and Schwartz, E.R. (Eds.), Marcel Dekker, NY, Part B, Vol 2, 953-978.

5. Genoni, M., Decurtins, M., Metzger, U., and Largiader, F. (1990). Omniflow: ein neue Gefassprothese fur Hamodialysezugange Helv. Chir. Acta, 57, 209-212.

6. Hait, M.R. (1970). Microcrystalline collagen. A new hemostatic agent. Amer. J. Surg., 120, 330.

7. Yannas, I.V., Burke, J.F., Gordon, P.L. and Huang, C. (1977). Multilayer membrane useful as a synthetic skin. U.S. Patent 4,060,081.

8. Doillon, C.J. and Silver, F.H. (1986). Collagenbased wound dressing: Effects of hyaluronic acid and fibronectin on wound healing. Biomaterials, 7, 3-8.

9. Wallace, D.G., McPherson, J.M., Ellingsworth, L., Cooperman, L., Armstrong, R. and Piez, K.A. (1988). Injectable collagen for tissue augmentation. In, Collagen, Vol.3, M.E. Nimni (Ed.), CRC Press, Boca Raton, FL, pp.117-144.

10. Herschom, S., Radomski, S.B. and Steele, D.J. (1992). Early experience with intraurethral collagen injections for urinary incontinence. $J$. Urol., 148, 1791-1800.

11. Brodsky, B., and Shah, N.K. (1995). The triple-helix motif in proteins. FASEB J., 9, 1537 1546.

12. Bateman, J.F., Lamande, S. and Ramshaw, J.A.M. (1995). Collagen. In, Extracellular Matrix: Vol. 2, Molecular Components and Interactions, Comper, W.D., (Ed.), Harwood Academic Publishers, Amsterdam, 22-67.

13. Brodsky, B., and Ramshaw, J.A.M. (1997). The collagen triple-helix structure. Matrix Biol., 15, 545-554.

14. Rosenbloom, J., Harsch, M., and Jimenez, S. (1973). Hydroxyproline content determines the denaturation temperature of chick tendon collagen. Arch. Biophys. Biochem., 158, 478-484.

15. Ramshaw, J.A.M., Shah, N.K. and Brodsky, B. (1998). Gly-X-Y tripeptide frequencies in collagen: a context for host-guest triple-helical peptides. J. Struct. Biol., 122, 86-91.

16. Yang, W., Chan, V.C., Kirkpatrick, A., Ramshaw, J.A.M. and Brodsky, B. (1997). Gly-Pro-Arg Confers stability similar to Gly-Pro-Hyp in the collagen triple-helix of host-guest peptides. J.Biol. Chem., 272, 28837-28840. 
17. Yamaguchi, M. and Mechanic, G.L. (1988). Cross-linking of Collagen. In, Collagen, Vol. 1, M.E. Nimni (Ed.), CRC Press, Boca Raton, FL, pp.157-172.

18. Ramshaw, J.A.M., Glattauer, V. and Werkmeister, J.A. (2000)., Stabilisation of Collagen in Clinical Applications. In, Biomaterials and Bioengineering Handbook, Wise, D.L. (Ed.), Marcel Dekker Inc, New York, pp. 717-738.

19. Werkmeister. J., A., and Ramshaw, J.A.M. (2000). Immunology of collagen-based biomaterials. In, Biomaterials and Bioengineering Handbook, Wise, D.L. (Ed.), Marcel Dekker Inc, New York, pp. 739-759.

20. Okoshi, T., Noishiki, Y., Tomizawa, Y., Morishima, M., Taera, T., Tadatomo, S., Itoh, H., Miyata, T., and Koyanagi, H. (1990). A new bioprosthetic cardiac valve with reduced calcification. ASAIO Trans., 36, M411-M414.

21. Miller, E.J. and Rhodes, R.K. (1982). Preparation and characterisation of the different types of collagens. Meth. Enzymol., 82, 33-64.

22. Weadock, K.S., Miller, E.J., Bellincampi, L.D., Zawadsky, J.P. and Dunn, M.G. (1995). Physical crosslinking of collagen fibers: comparison of ultraviolet irradiation and dehydrothermal treatment. J.Biomed. Mater. Res., 29, 1373-1379.

23. Edwards, G.A., Glattauer, V., Nash, T.J., White, J.F., Brock, K.A., Werkmeister, J.A., and Ramshaw, J.A.M. (1997). In vivo evaluation of a collagenous membrane as an absorbable adhesion barrier. J.Biomed. Mater. Res., 34, 291-297.

24. De Vore, D.P., Scott, J.B., Hughes, E. and Skelnick, D. (1994). Viscoelastic collagen solution for use in cataract surgery. Proceedings, 20th Annual Meeting, Society for Biomaterials, Birmingham, p.130.

25. Rodkey, W.G., Steadman, J.R., and Li, S-T. (1999). A clinical study of collagen meniscus implants to restore the injured meniscus. Clin. Orthop. Rel. Res., 367S, S281-S292.

26. Myllyharju, J. (2000). Recombinant collagen trimers from insect cells and yeast. Meth. Mol. Biol., 139, 39-48.

27. Vaughan P.R., Galanis, M., Ramshaw, J.A.M. and Werkmeister, J.A. (1997). Stable expression of the triple helical proteins. PCT/AU97/00721.

28. Fertala, A., Sieron, A.L., Ganguly, A., Li, S.W., Ala-Kokko, L., Anumula, K.R. and Prockop, D.J. (1994). Synthesis of recombinant human procollagen II in a stably transfected tumour cell line (HT1080). Biochem. J., 298, 31-37.

29. Lamberg, A., Helaakoski, T., Myllyharju, J., Peltonen, S., Notbohm, H., Pihlajaniemi, T. and Kivirikko, K.I. (1996). Characterisation of human type III collagen expressed in baculovirus system: production of a protein with a stable triple helix requires coexpression with two types of recombinant prolyl 4-hydroxylase subunit. $J$. Biol. Chem., 271, 11988-11995.

30. Myllyharju, J., Lamberg, A., Notbohm, H., Fieztek, P.P., Pihlajaniemi, T. and Kivirikko, K.I. (1997). Expression of wild-type and modified pro- $\alpha$ chains of human type I procollagen in insect cells leads to the formation of stable $\left[\alpha 1(\mathrm{I})_{2}\right] \alpha 2(\mathrm{I}) \mathrm{col}-$ lagen heterotrimers and $[\alpha(\mathrm{I})]_{3}$ homotrimers but not $[\alpha 2(\mathrm{I})]_{3}$ homotrimers. J. Biol. Chem., 272, 21824-21830.

31. Cappello, J. (1993). High molecular weight collagen-like protein polymers. U.S. Patent $5,773,249$

32. Weber, S.C., and McElver, J.A. (1997). Collagen-like polypeptides and biopolymers and nucleic acids encoding same. U.S. Patent $5,670,616$.

33. Prockop, D.J., Ala-Kokko, L., Fertala, A., Sieron, A., Kivirikko, K.I. and Geddis, A. (1993). Synthesis of human procollagens and collagens in recombinant DNA systems. U.S. Patent 5,593,859.

34. Vaughan, P.R., Galanis, M., Richards, K.M., Tebb, T.A., Ramshaw, J.A.M. and Werkmeister, J.A. (1998). Production of recombinant hydroxylated human type III collagen fragment in Saccharomyces cerevisiae. DNA Cell Biol., 17, 511-518.

35. Toman, P.D., Chisolm, G., McMullin, H., Giere, L.M., Olsen, D.R., Kovach, R.J., Leigh, S.D., Fong, B.E., Chang, R., Daniels, G.A., Berg, R.A., and Hitzeman, R.A. (2000). Production of recombinant human type I procollagen trimers using a four-gene expression system in the yeast Saccharomyces cerevisiae. J. Biol. Chem., 275, 23303-23309.

36. Toman, P.D., Berg, R.A., Daniels, G.A., Hitzeman, R.A., and Chisolm, G.E. (1997). Production of recombinant procollagen in yeast. International Patent Application WO 97/14431.

37. de Bruin, E.C., de Wolf, F.A. and Laane, N.C.M. (2000). Expression and secretion of human alpha 1(I) procollagen fragment by Hansenula polymorpha as compared to Pichia pastoris. Enz. Microbial Technol., 26, 640-644.

38. Myllyharju, J., Nokelainen, M., Vuorela, A. and Kivirikko, K.I. (2000). Expression of human type I-III collagens in the yeast Pichia pastoris. Biochem. Soc. Trans. 2000, 28, 353-357.

39. Ruggiero, F., Exposito, J-Y., Bournat, P., Gruber, V., Perret, S., Comte, J., Olangnier, B., Garrrone, R. and Theisen, M. (2000). Triple helix assembly and processing of human collagen produced in transgenic tobacco plants. FEBS Lett., 469, 132-136.

40. Berg, R.A. (1994). Production of human recombinant collagen in the milk of transgenic animals. International Patent Application WO 
$94 / 16570$.

41. Toman, D.P., Pieper, F., Sakai, N., Karatzas, C., Platenburg, E., de Wit, I., Samuel, C., Dekker, A., Daniels, G.A., Berg, R.A. and Platenburg, G. (1999). Production of recombinant human type I procollagen homotrimer in the mammary gland of transgenic mice. Transgen. Res., 8, 415-427.

42. John, D.C., Kind, R., Scott, A.J., Kadler, K.E. and Bulleid, N.J. (1999). Expression of an engineered form of recombinant procollagen in mouse milk. Nature Biotechnol., 17, 385-389.

43. Pierce, E.C. and Baltimore, M.D. (1953). Autologous tissue tubes for aortic grafts in dogs. Surgery, 33, 648-657.

44. Hufnagel, C.A. (1964). Discussion. Annal Surg., 159, 828.

45. Assefi, I. and Parsonnet, V. (1964). An arterial prosthesis composed of an autogenous fibrocollagenous tube with incorporated polypropylene mesh. J. Newark Beth Israel Hosp., 15, 161-170.

46. Sparks, C.H. (1969). Autogenous grafts made to order. Ann. Thor. Surg., 8, 104-113.

47. Parsonnet, V., Alpert, J. and Brief, D.K (1971). Autogenous polypropylene-supported collagen tubes for long-term arterial replacement. Surgery, 70, 935-939.

48. Parsonnet, V., Tiro, A.C., Brief, D.K., Alpert, J. and Brener, B.J. (1978). The fibrocollagenous tube as a small arterial prosthesis. In: Graft $M a$ terials in Vascular Surgery, ed. H. Dardik. Symposia Specialists, Miami.

49. Nimni, M.E., Cheung, D.T., Strates, B.,Kodama, M., and Sheikh, K (1988). Bioprosthesis derived from cross-linked and chemically modified collagenous tissues. In: Collagen, vol 3, CRC Press, Boca Raton, FL, pp., 1-38.

50. Dardik, H., Ibrahim, I.M., Srayregen, S. and Dardik, 1.I. (1976). Clinical experience with modified human umbilical cord vein for arterial bypass. Surgery, 79, 618-624.

51. White, J.F., Werkmeister, J.A., Edwards, G.A. and Ramshaw, J.A.M. (1993). Structural analysis of a collagen-polyester composite vascular prosthesis. Clin. Materials, 14, 271-276.

52. Edwards, G.A. and Roberts, G. (1992). Development of an ovine collagen-based composite vascular prosthesis. Clin. Materials, 9: 211-223.

53. Koch, G., Gutschi, S., Pasher, O., Fruhwirth, J. and Hauser, H. (1996). Zur problematik des femoropoplitealen Gefaßersatzes: Vene, ePTFE oder ovines Kollagen? Zentralbl. Chir., 121, 761-767.

54. O’Donnell, T.F., Mackey, W., McCullough, J.L., Maxwell, S.L., Farber, S.P., Deterling, R.A. and Callas, A.D. (1984). Correlation of operative findings with angiographic and non-invasive hemodynamic factors associated with failure of polytetrafluoroethylene grafts. J. Vasc. Surg., 1, 136-148.

55. Kidson, I.G. (1983). The effect of wall mechanical properties on patency of arterial grafts. Ann. Roy. Col. Surg. Eng., 65, 24-29.

56. Werkmeister, J.A., Glattauer, V., Tebb, T.A., Ramshaw, J.A.M., Edwards, G.A. and Roberts, G. (1991). Structural stability of long-term implants of a collagen-based vascular prosthesis. $J$. Long-term Effects Med. Implants, 1, 107-119.

57. Werkmeister, J.A., Edwards, G.A., and Ramshaw, J.A.M. (2000). Collagen-based vascular prostheses. In: Biomaterials Engineering and Devices: Human Applications, vol 1, Humana Press Inc., New Jersey, Wise, D.L. (ed), pp. 121-136.

58. Hasson, J.E., Newton, D., Waltman, A.C., Fallon, J.T., Brewster, D.C., Darling, C. and Abbott, W.M. (1986). Mural degeneration in glutaraldehyde-tanned umbilical vein graft: Incidence and implications. J. Vasc. Surg., 4, 243-250.

59. Werkmeister, J.A., Peters, D.E. and Ramshaw, J.A.M. (1989). Development of monoclonal antibodies to collagens for assessing host-implant interactions. J. Biomed. Materials Res.: Appl. Biomaterials, 23(A3), 273-283.

60. Werkmeister, J.A., Ramshaw, J.A.M. and Ellender, G. (1990). Characterisation of a monoclonal antibody against native human type I collagen. Eur. J. Biochem., 187, 439-443.

61. Werkmeister, J.A. and Ramshaw, J.A.M. (1991). Multiple antigenic determinants on type III collagen. Biochem. J, 274, 895-898.

62. Werkmeister, J.A. and Ramshaw, J.A.M. (1991). Monoclonal antibodies to type $\mathrm{V}$ collagen as markers for new tissue deposition associated with biomaterial implants. J. Histochem. Cytochem., 39, 1215-1220.

63. Werkmeister, J.A., Tebb, T.A., White, J.F and Ramshaw, J.A.M. (1993). Monoclonal antibodies to type VI collagen demonstrate new tissue augmentation of a collagen-based biomaterial implant. J. Histochem. Cytochem., 41, 1701-1706.

64. Werkmeister, J.A., White, J.F. and Ramshaw, J.A.M. (1994). Evaluation of the Omniflow collagen-polymer vascular prosthesis. Med. Prog. Technol, 20, 231-242.

65. Werkmeister, J.A., White, J.F. Edwards, G.A. and Ramshaw, J.A.M. (1995) Early performance appraisal of the Omniflow II vascular prosthesis as an indicator of long-term function. $J$. Longterm Effects Med Implants, 5, 1-10.

66. Werkmeister, J.A., White, J.F., Edwards, G.A., and Ramshaw, J.A.M. (1995) Evaluation of the Omniflow collagen-polymer vascular prosthesis: immunohistological analysis using monoclonal antibodies. In, Materials in Clinical Applications, Vincenzini, P. (Ed.), Techna, 769- 
776.

67. Yoshida, H., Sasjima, T., Goh, K., Inaba, M., Otani, N., and Kubo, Y. (1996). Early results of a reinforced biosynthetic ovine collagen vascular prosthesis for small arterial reconstruction. Surg. Today, 26, 262-266.

68. Koch, G., Gutschi, S., Pasher, O., Fruhwirth, J. and Glanzer, H. (1997). Analysis of $274 \mathrm{Om}$ niflow Vascular Prostheses implanted over an eight year period. Aust. N.Z. J. Surg., 67, 637639.

69. Werkmeister, J.A., Edwards, G.A., White, J.F., Casagranda, F., Hunt, J.A., Williams, D.F. and Ramshaw, J.A.M. (1999). In vivo evaluation of modified mandrel grown vascular prostheses. J.Biomed. Materials Res., 47, 316-323.

70. Werkmeister, J.A., Edwards, G.A., Casagranda, F., White, J.F. and Ramshaw, J.A.M. (1998). Evaluation of a collagen-based biosynthetic material for the repair of abdominal wall defects. $J$. Biomed. Materials Res., 39, 429-436.

71. Young, R.L., Cota, M.D., Zund, G., Mason, B.A. and Wheeler, J.M. (1991). The use of an amniotic membrane graft to prevent postoperative adhesions. Fertil. Steril., 55, 624-628.

72. Diamond, M.P., Linsky, C.B., Cunningham, T., Constantine, B., di Zerega, G.S. and DeCherney, A.H. (1987). A model for sidewall adhesions in the rabbit: reduction by an absorbable barrier. Microsurgery, 8, 197-200.

73. Sawhney, A.S., Pathak, C., vanRensburg, J.J., Dunn, R.C., and Hubbell, J.A. (1994). Optimization of photopolymerized bioerodible hydrogel properties for adhesion prevention. J. Biomed. Materials Res., 28, 831-838.

74. Urman, B., Gomel, V., and Jetha, N. (1991). Effect of hyaluronic acid on postoperative intraperitoneal adhesion prevention in the rat model. Fertil. Steril., 56, 563-567.

75. INTERCEED (TC7) Adhesion Barrier Study Group. (1989). Prevention of postsurgical adhesions by INTERCEED (TC7), an absorbable adhesion barrier: a prospective, randomized multicenter clinical study. Fertil. Steril., 51, 933938.

76. Ellender, G., Hammond, R., Papli, R., Mitrangas, K., Bateman, J.F., Glattauer, V., Thyer, J.M., Werkmeister, J.A. and Ramshaw, J.A.M. (1992). Osteogenic capacity of collagen in repair of established periodontal defects. Clin. Materials 9, 201-209.

77. Nyman, S., Lindhe, J., Karring, T., and Rylander, H. (1982). New attachment following surgical treatment of human periodontal disease. J. Clin. Periodontol., 9, 290-296.

78. Polarek, J.W. (2000). Use of recombinant human collagen as a biomaterial. Proceedings, $6^{\text {th }}$
World Biomaterials Congress, Hawaii, p.129.

79. Yang, C., Tang, J., Sahai, A., Folz, A., Duffy, R., Ho, F., Bodo, M., Perälä-Heape, M., Hämäläinen, E-R. and Polarek, J. (2000). Recombinant human collagen III as a biomaterial for hemostatic applications. Proceedings, $6^{\text {th }}$ World Biomaterials Congress, Hawaii, p. 1093.

80. Knight, C.G., Morton, L.F., Peachey, A.R., Tuckwell, D.S., Farndale, R.W. and Barnes, M.J. (2000). The collagen-binding A-domains of integrins alpha(1)beta(1) and alpha(2)beta(1) recognize the same specific amino acid sequence, GFOGER, in native (triple-helical) collagens. $J$. Biol. Chem., 275, 35-40.

81. Glattauer,V., Werkmeister, J.A., Kirkpatrick, A. and Ramshaw, J.A.M. (1997). Identification of the epitope for a monoclonal antibody that blocks platelet aggregation induced by type III collagen. Biochem. J., 323, 45-49.

82. Kadler, K. (1994). Extracellular matrix 1: fibrilforming collagens. Protein Profile 5(1).

83. Martin, S.L., Vrhovski, B. and Weiss, A.S. (1995). Total synthesis and expression in Escherichia coli of a gene encoding human tropoelastin. Gene, 154, 159-166.

84. Persikov, A.V., Ramshaw, J.A.M., Kirkpatrick, A. and Brodsky, B. (2000). Amino acid propensities for the collagen triple-helix. Biochemistry, 39, 14960-14967.

85. Dardik, H., Miller, N., Dardik, A., Ibrahim, I.M., Sussman, B., Berry, S.M., Wolodiger, F., Kahn, M., and Dardik, I. (1988). A decade of experience with the glutaraldehyde-tanned human umbilical cord vein graft for revascularisation of the lower limb. J. Vasc. Surg., 7, 336-346.

86. Schoen, F.J. and Levy, R.J. (1984). Bioprosthetic heart valve failure: Pathology and pathogenesis. Cardiol. Clinics, 2, 717-739.

87. Yaffe, A., Ehrlich, J. and Shoshan, S. (1984). Restoration of periodontal attachment employing enriched collagen solution in the dog. J. Periodontol., 55, 623-628.

88. Mehlisch, D.R., Taylor, T.D., Leibold, D.G., Hiatt, R., Waite, D.E., Waite, P.D., Laskin, D.M. and Smith, S.T. (1988). Collagen/hydroxyapatite implant for augmenting deficient alveolar ridges: Twelve month clinical data. J. Oral Maxillofacial Surg., 46, 839-843.

89. Knapp, T.R., Kaplan, E.N. and Daniels, J.R. (1977). Injectable collagen for soft tissue augmentation. Plast. Reconstruct. Surg., 60, 398-405.

90. Doillon, C.J., Whyne, C.F. Brandwein, S. and Silver, F.H. (1986). Collagen-based wound dressings: Control of the pore structure and morphology. J. Biomed. Materials Res., 20, 1219-1228.

91. Remacle, M., Hamoir, M. and Marbaix, E. (1990). 


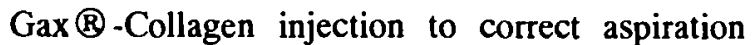
problems after subtotal laryngectomy. Laryngoscope, 100, 663-669.

92. Natsume, T., Ike, O., Okada, T., Takimoto, N., Shimizu, Y. and lkada, Y. (1993). Porous collagen sponge for esophageal replacement. $J$. Biomedical Mat. Res., 27, 867-875.

93. Adler , R.H., Pelecanos, N.T., Rosenzweig, S.E. and Thorsell, H.G. (1962). A collagen mesh prosthesis for wound repair and hernia reinforcement. Surgical Forum, 13, 29-31.

94. James, N.L., Poole-Warren, L.A., Schindhelm, K., Milthorpe, B.K., Mitchell, R.M. and Howlett, C.R. (1991). Comparative evaluation of treated bovine pericardium as a xenograft for hernia repair. Biomaterials, 16, 801-809.

95. Young, R.L., Cota, M.D., Zund, G., Mason, B.A. and Wheeler, J.M. (1991). The use of an amniotic membrane graft to prevent postoperative adhesions. Fertil. Steril., 55, 624-628.

96.Tardy, M., Gravaagna, P., Revet, L., Uhlrich. S., Tiollier, J. and Tayot, J.L. (1995) New surgical sealant (glue) based on controlled oxidised collagen. Proceedings, 21st Annual Meeting, Society for Biomaterials, San Francisco, p.254.

97. Yannas I.V. (1988). Regeneration of skin and nerve by use of collagen templates. In, Collagen, Vol. 3, M.E. Nimni (Ed.), Boca Raton, FL, CRC Press, pp. 87-115.

98.Li, S-T., Archibald, S.J., Krarup, C. and Madison, R.D. (1992). Peripheral nerve repair with collagen conduits. Clin. Materials, 9, 195-200.

99.Rizvi, A.H., Pins, G.D. and Silver, F.H. (1994). Peripheral nerve regeneration in the presence of collagen fiber: Effect of removal of the distal nerve stump. Clin. Materials 16, 73-80.

100. Ruffini, J.J., Aquavella, J.V. and LoCascio, J.A. (1989). Effect of collagen shields on corneal epithelialization following penetrating keratoplasty. Ophthal. Surg., 20, 21-25.

101. L'Esperance, F.A., Jr. (1965). Reconstituted collagen tape in retinal detachment surgery. Arch. Ophthalmol, 73, 472-475.

102. Deporter, D.A., Komori, N., Howley, T.P., Shiga, A., Ghent, A. , Hansel, P. and Parisien, K.
(1988). Reconstituted bovine skin collagen enhances healing of bone wounds in the rat calvaria. Calcif. Tissue Internat., 42, 321-326.

103. Stastny, K., Hora, K. and Stol, M. (1993). Preliminary report on use of a $\mathrm{p}$ (HEMA)-collagen composite in maxillo-facial surgery. Biomaterials, 14, 1105-1108.

104. Speer, D.P., Chvapil, M., Voltz, R.G., Holmes, M.D. (1979). Enhancement of healing in osteochondral defects by collagen sponge implants. Clin. Orthop. Rel. Res., 144, 326-335.

105. Stone, K.R., Rodkey, W.G., Webber, R.J., McKinney, L. and Steadman, J.R. (1990). Future directions. Collagen-based prostheses for meniscal regeneration. Clin. Orthop., 252, 129135.

106. Chvapil, M., Speer, D.P., Holubec, H., Chvapil, T.A. and King, D.H. (1993). Collagen fibers as a temporary scaffold for replacement of ACL in goats. J. Biomed. Mat. Res., 27, 313-325.

107. Salen, B. and Simbach, I. (1965). Exogenous collagen in the closure of tympanic membrane perforations. J. Lanryngol Otol., 79, 159-165.

108. Abbenhaus, J.I. and Hemenway, W.G. (1967). Bovine collagen as tympanic membrane graft in dogs. Surgical Forum, 18, 490-491.

109. Tachinaba, M. Naganatsu, G.R. and Addonizio, J.C. (1985). Uretal replacement using collagen sponge tube grafts. J. Uroh, 133, 866-869.

110. Tanner, J.C., Marcucci, M.A. and Bradley, W.H. (1968). Partial nephrectomy and use of collagen grafts for renal wound closure. J. Urol., 99, 710712.

111. Stenzel, K.H., Sullivan, J.F., Miyata, T. and Rubin A.L. (1969). Collagen dialysis membranes: Initial clinical evaluation. ASAIO Trans., 15, 114-117.

112. Gilbert, D.L. and Kim S.W. (1990). Macromolecular release from collagen monolithic devices. J. Biomed. Mat. Res., 24, 1221-1239.

113. McPherson, J.M. (1992). The utility of collagen-based vehicles in delivery of growth factors for hard and soft tissue wound repair. Clin. Materials, 9, 225-234. 